resent being defined by their trait. Medical geneticists have had to adapt to patients' views of themselves.

To justify morally the genetic-screening programmes she writes about, Cowan cites the good intentions of the parties involved, primarily their efforts to relieve suffering. This criterion does not pass philosophical muster, nor is it sufficient to sway vehement opponents. Although her analysis is cursory, it does get to the heart of the matter: hereditary diseases cause great human suffering and everyone wants to help.

What no commentator on medical genetics acknowledges is the hidden sadness, customarily buried, that each geneticist feels when discussing with patients and parents the options for treatment, which are generally few and unsatisfactory. This takes its toll on everyone, although patients always astound with their resilience.

The hard truth is that genetics does not offer easy answers. There are many genetic diseases, and each one is unique. The simplicity of DNA is illusory - our DNA is popularly regarded as our medical fate, but DNA interrogations more often yield notions of risk that have different meanings to patients and physicians. Physicians rarely know the true cause of our complaints. In those genetic cases where simplicity prevails, the testing technology is likely to be adopted. As law in the United States, the Genetics Information Non-discrimination Act may relieve some anxiety about the misuse of genetic information. If only it were so simple to dispatch misery.

Modern healers may claim science to be the foundation of their work, but the key is, in fact, persuasion: to heed advice, to push and persevere, to hope. As the genome is further dissected and better understood, no family of diseases warrants more genuine hope for successful management than genetic conditions. Cowan understands that we must all share that hope for the campaign to be successful.

Hugh Young Rienhoff Jr is director of MyDaughtersDNA.org, based in San Francisco, California, USA.

\title{
A rough guide to Titan
}

\section{Titan Unveiled: Saturn's Mysterious Moon Explored by Ralph Lorenz and Jacqueline Mitton Princeton University Press: 2008. 296 pp. $\$ 29.95, £ 17.95$}

A future tourist guidebook to this remote destination would warn us to bring our heavyduty rain gear, but be prepared not to need it. Droughts may last many years there, but when a hurricane-sized storm sweeps across the sky, the rainfall is torrential. At high latitudes, the landscape is dotted with thousands of lakes, some mere ponds and others inland seas. Networks of channels and canyons are etched into the terrain, over which huge volcanic domes loom. Other regions harbour vast fields of dunes, some 100 metres high. Welcome to Titan, Saturn's largest moon.

Our guidebook would go on to explain that the dune particles are not sand, but hydrocarbons, totalling more than all the coal reserves on Earth. The magma flowing from the volcanoes is not liquid rock, but a mix of ammonia and water, similar to antifreeze. Liquid ethane fills the lakes. And liquid methane carved the gullies at rates far in excess of the worst flash-flooding on Earth.

Titan Unveiled, by planetary scientist Ralph Lorenz and astronomy writer Jacqueline Mitton, presents a good overview of the state of our knowledge of this curious moon, and is accessible to most. Lorenz is closely involved with the Cassini mission to Saturn and the Huygens probe it dropped onto Titan's surface in 2005. The book focuses on his key interests, which include Titan's surface and lower atmosphere, regions that parallel Earth and are thus the most engaging for readers.

Titan Unveiled describes how most of what we once hypothesized about Titan has been proved wrong. The story of how we gained our current knowledge is fascinating; even more intriguing is what remains to be learned. Larger than Mercury, Titan is the only moon in our Solar System that is enveloped in a thick atmosphere. Analogous to Earth's water-based weather system, Titan's atmosphere experiences weather based on the phase changes of methane, shifting between its gas, liquid and solid states. At the extremely cold temperatures on Titan's surface $\left(94 \mathrm{~K}\right.$, or $\left.-179^{\circ} \mathrm{C}\right)$, water is frozen and acts like rock. The moon is geologically active, including volcanism and uplifting of mountain ranges. Deep under the icy surface, evidence for an ocean of liquid water and ammonia has been found.

Scattered throughout the text are personal anecdotes by Lorenz, labelled "Ralph's Log". Key to the book's success, these sections

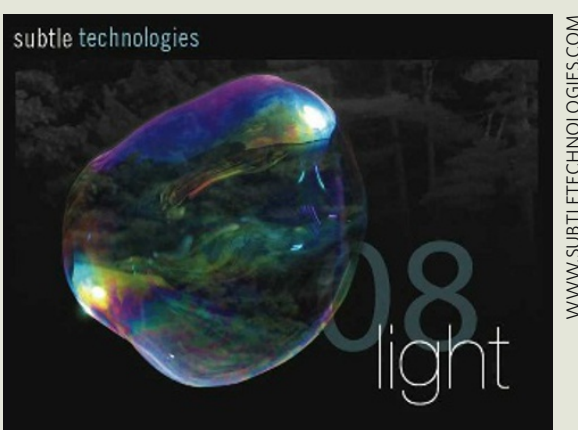

\section{NORTHERN LIGHTS}

The many shades of light in art and science are the focus of the annual Subtle Technologies Festival in Toronto, Canada, starting this week. A symposium (from 30 May to 1 June) will discuss the physics of light, its use in education, photography, performance, new media and architecture. Sound artists muse about synaesthesia; a physicist explains why painters love the light in Provence, France; and a biologist describes how to image cells.

www.subtletechnologies.com

\section{GREEN FINGERS}

Gardeners are the canaries of climate change: first to notice buds blooming early, lawns that need mowing more often and pests spreading in range as average temperatures creep up. This week's Chelsea Flower Show in London (until 24 May), run by the Royal Horticultural Society, includes scientific exhibits to educate plant lovers about climate change. UK researchers from the Tyndall Centre in Norwich, the University of Reading, Rothamsted Research in Harpenden, and others will be on hand to explain how plants, ecosystems and practices must adapt. www.rhs.org.uk/chelsea/2008

\section{BEING HUMAN}

An exploration of what it means to be human in a rapidly changing world and vast Universe is the theme of the 55th Carnegie International. The largest US survey of contemporary art, it opened this month at Pittsburgh's Carnegie Museum of Art (until January 2009). Life on Mars, named after David Bowie's song, offers 300 works from 40 international artists, including Vija Celmins, who received the US\$10,000 Carnegie Prize for her Night Sky series of paintings.

www.cmoa.org

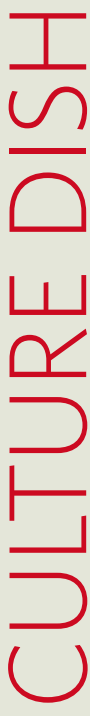


convey how planetary exploration, and science in general, progresses as a human enterprise. Lorenz communicates what it is like to be a scientist involved with a current space mission, working with diverse colleagues and following your curiosity to make new discoveries.

Advances may come serendipitously, but they are usually hard-won following years of intense work, carried out with the risk of failure and research dead-ends. Some obstacles to progress are simple to overcome. For example, Lorenz recounts how, while working alone at night at an observatory, he was once held back by a crucial piece of equipment that lay behind a locked storage-room door. His eventual solution was to remove the door's hinges. Other challenges are greater, such as the discovery of an engineering problem with the radio transmitter on the

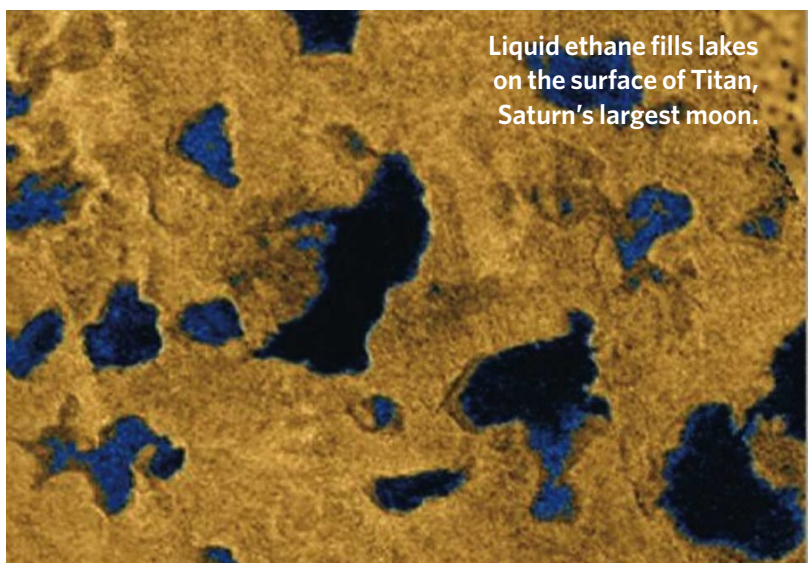

it from Earth nearly every night, new discoveries are regular. It is inevitable that any book on Titan is a little outof-date before it is released, but this reflects the vitality of the research.

We won't be able to book a ticket to Titan in the next few decades, but further robotic spacecraft will be sent to explore. A Titan orbiter could map the surface, observe the seasonal weather patterns and study the subsurface ocean. Balloon-borne detectors could examine the atmosphere and surface up close. And a new mission will add detail to our guidebook to Titan. Hopefully,

Huygens probe after its launch. It required a major effort to retarget and replan nearly the entire mission, involving hundreds of people and thousands of hours of work.

With the Cassini mission flying past Titan every few weeks and astronomers observing someone working on that mission will write an insider's account, like Titan Unveiled, to tell us how it all happened.

Henry Roe is an astronomer at Lowell Observatory, 1400 West Mars Hill Road, Flagstaff, Arizona 86001, USA.

\section{How science hit the small screen}

\begin{abstract}
Films of Fact
Science Museum, London

From 29 May to 2 November 2008.

Films of Fact: A History of Science in

Documentary Films and Television

by Timothy Boon

Wallflower Press: 2008. 224 pp.

$£ 45.00$ (hbk), £16.99 (pbk)
\end{abstract}

"Is it not a scandal, in this day and age, that there seems to be no place for continuing series of programmes about science?" asked veteran natural history broadcaster David Attenborough, lecturing on the future of public service television in London on 30 April. "If you want an informed society, there has to be a basic understanding of science."

An exhibition opening next week at London's Science Museum, Films of Fact, charts how science was introduced to the UK public in documentary films and on television in the early twentieth century, from the birth of these media to the 1960s.

Animals and plants featured in the first science films made for public viewing. Lasting for 56 seconds, the 1903 film Cheese Mites was first screened at London's Alhambra Music Hall as part of a musical and theatrical playbill that included ballet and magic tricks. Filmed down a microscope by amateur natural historian Francis Martin Duncan, the greatly magnified mites scuttle about. They may not seem riveting to our jaded eyes, but they stimulated demand for nature-based films. Producer Charles Urban exploited this commercial potential in a series of photomicrography films called 'The Unseen World: Revealing Nature's Closest Secrets by Means of the Urban-Duncan Micro-Bioscope', which included The Circulation of the Protoplasm of the Canadian Waterweed (1903). Nature series quickly became established as a popular genre and remain so today, from movies of meerkat antics to marching penguins.

The most successful nature film series

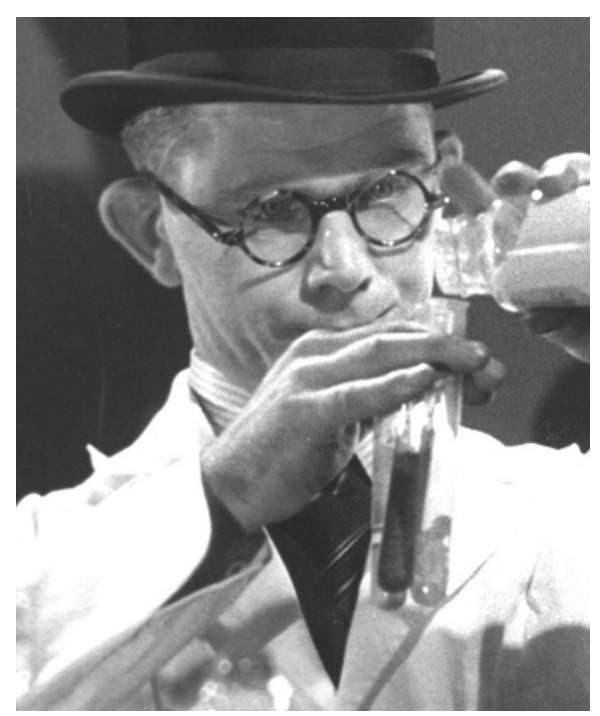

Comic chemistry: Rotha's 1938 New Worlds for Old. before the Second World War was Secrets of Nature (1922-33), produced by British Instructional Films. Its successor was Secrets of Life (1934-50). Celebrated cameraman Percy Smith, a clerk at the UK government's Department of Education, worked on both series. He specialized in filming through microscopes or glass aquaria in his London greenhouse, using a timing device he made from a cuckoo clock to record plant growth with time-lapse photography.

Television programming about science took off in the mid-1950s in the United Kingdom, two decades after broadcasting began there in 1936. Some science series were designed to teach. Producers and scientists worked together, mostly in live broadcasts such as Eye on Research (1957-61), which took cameras into research establishments.

As television became a mass medium, scientists tried to influence how broadcasters represented science, but they did not always get a good reception. "Priority must be given to the medium rather than scientific pedantry," ruled Aubrey Singer, head of the BBC's science department in 1966. "The aim of scientific programming ... is not necessarily the propagation of science" but "an enrichment of the audience experience". Similar attitudes prevail today.

Other documentaries, many commercially sponsored, explored how new technologies were transforming everyday life. Influential film-maker Paul Rotha's 1933 documentary Contact, sponsored by Imperial Airways, captures aeroplane manufacture using beguiling and original cinematography. From the 